\title{
Malaria: An Old Disease, Still Relevant Today
}

\author{
Patrice Bourée $\mathbf{1}^{1 *(1)}$ \\ ${ }^{1}$ Tropical Depart, Institut Alfred Fournier, 75014 Paris, France
}

W hen children and adults are asked which animal is the most dangerous, they regularly cite the shark, the lion, the crocodile and the serpent. In fact, the shark kills 10 people a year, the lion 200 people, the crocodile 1000 people, and the snake 100000 people. However, in reality, the most dangerous animal is very small, namely the mosquito, which kills 800000 people a year. Depending on the species and the regions, mosquitoes inoculate dangerous viruses (such as yellow fever virus), parasites (Plasmodium), and a lot of less dangerous viruses (dengue, chikungunya, Zika, Japanese encephalitis, etc) which are responsible for fever and severe fatigue.

Parasitic diseases cause significant morbidity and mortality in the world, especially in tropical countries. Malaria is the most common and potentially deadly parasitic disease (1). Four species of malaria parasites are known to infect humans, including Plasmodium falciparum, Plasmodium vivax, $P$. ovale, and $P$. malariae which cause significant morbidity. $P$. knowlesi, which is responsible for daily peaks in Malaysia, has been shown to be dangerous for humans. Plasmodium ovale is now divided into two subspecies, $P$. ovale curtisi and $P$. ovale wallikeri. Molecular biology techniques allow better identification of species and follow their geographical distribution. Knowledge about malaria is increasing every day $(2,3)$.

Despite the progress already made in the fight against malaria with a better information given to the population and a wide distribution of mosquito-nets, this disease remains a scourge of public health. Malaria has existed since the existence of human beings and has been treated with a Chinese plant named Qing hao-su, which has been used in herbal tea for more than 2000 years in China.

Drugs used for several decades such as Quinine and Chloroquine have become ineffective, which require the use of other structures, including some new structures such as like Atovaquone and others with a return to traditional Chinese plants such as artemisinin. However, here again, resistance phenomena are starting to appear

\begin{abstract}
Author's Biosketch
Professor Patrice Bourée was for 40 years the head of the Parasitic and Tropical Diseases Department of the Paris IX Uniiversity. Professor at the College of Medicine in Paris, he is currently a Consultant Professor at the Alfred-

Fournier Institute, which is a renowned medical center of infectious diseases. He worked on different subjects of tropical pathology (bilharziosis, filariosis, amoebiasis, malaria...) in Africa, south America, Pacific islands and recently in Mayotte (Indian Ocean) on leprosy. He was the first to describe, in 1976, an outbreak of human trichinellosis due to horse meat, which is well known today. More than 1700 scientific papers written by Patrice Bourée .He has published several books, in French, the most recent of which are : Aide-mémoire of Parasitology 400p, Pregnancy and Tropical Pathology 200p, Parasitology and Mycology in pocket 105p. He is Commander of The Academic Palms of the University and member of several scientific societies.
\end{abstract}

and the search for new structures is always necessary (4). Recently, under a humanitarian pretext, a company wanted to take up the idea of an artemisinin-based herbal tea. Certainly, this "magic potion" is accessible to all population groups, but it is a therapeutic error because the dose administered in herbal tea is extremely variable and insufficient to prevent or treat malaria, and, above all, this method is the best way to develop resistance to artemisinin. Therefore, it is therefore necessary to preserve the effectiveness of existing structures as much as possible while improving the standard of living of population. Indeed, malaria is a parasitic disease of poverty, with a morbidity of around 200 million people per year and a mortality of 500000 per year. The majority of patients are children under 5 years old and $80 \%$ of them are identified in sub-Saharan Africa and India (5).

According to the WHO report, 54 trillion people have died of malaria since antiquity. It is estimated that malaria costs around 12 billion dollars a year. It is necessary to encourage international organizations to fight against 
malaria through prevention, as well as diagnostic and therapeutic means, including vaccine research. The "Roll Back Malaria" initiative was launched by WHO mainly to reduce the malaria burden in Africa and did not initially address malaria elimination (6). However, it is feared that malaria will still claim many lives before it may disappear one day.

\section{Ethical Statement}

Not applicable.

\section{Conflict of Interests}

None.

\section{References}

1. Malaria [website]. Geneva: World Health Organization; 2019. https://www.who.int/malaria/en/. Accessed June 16, 2020.

2. Malaria case management: operations manual. Geneva:
World Health Organization; 2009. (https://www.who.int/ malaria/publications/atoz/9789241598088/en/. Accessed June 17, 2020.

3. Carter KH, Singh P, Mujica OJ, et al. Malaria in the Americas: trends from 1959 to 2011. Am J Trop Med Hyg. 2015;92(2):302-316. doi:10.4269/ajtmh.14-0368

4. Seasonal malaria chemoprevention with sulfadoxinepyrimethamine plus amodiaquine in children: a field guide. Geneva: World Health Organization; 2013. https:// www.who.int/malaria/publications/atoz/9789241504737/ en/. Accessed June 17, 2019.

5. Mass drug administration for falciparum malaria: a practical field manual. Geneva: World Health Organization; 2017. https:// www.who.int/malaria/publications/ atoz/9789241513104/en/. Accessed June 17, 2020.

6. malERA Consultative Group on Health Systems and Operational Research. A research agenda for malaria eradication: health systems and operational research. PLoS Med. 2011;8(1):e1000397. doi:10.1371/journal. pmed.1000397

(C) 2020 The Author(s); This is an open-access article distributed under the terms of the Creative Commons Attribution License (http:// creativecommons.org/licenses/by/4.0), which permits unrestricted use, distribution, and reproduction in any medium, provided the original work is properly cited. 